\title{
Lidil
}

Revue de linguistique et de didactique des langues

\section{Marcellesi Jean-Baptiste, Sociolinguistique : épistémologie, langues régionales, polynomie}

2003, textes réunis par Thierry Bulot et Philippe Blanchet, L'Harmattan.

\section{Marielle Rispail}

\section{OpenEdition}

\section{Journals}

Édition électronique

URL : http://journals.openedition.org/lidil/43

DOI : $10.4000 /$ lidil.43

ISSN : 1960-6052

\section{Éditeur}

UGA Éditions/Université Grenoble Alpes

Édition imprimée

Date de publication : 1 décembre 2006

ISBN : 2-914176-15-5

ISSN : $1146-6480$

Référence électronique

Marielle Rispail, « Marcellesi Jean-Baptiste, Sociolinguistique : épistémologie, langues régionales, polynomie », Lidil [En ligne], 34 | 2006, mis en ligne le 01 février 2007, consulté le 21 septembre 2020. URL : http://journals.openedition.org/lidil/43 ; DOI : https://doi.org/10.4000/lidil.43

Ce document a été généré automatiquement le 21 septembre 2020

(C) Lidil 
Marcellesi Jean-Baptiste, Sociolinguistique : épistémologie, langues régionales, polynomie 2003, textes réunis par Thierry Bulot et Philippe Blanchet, L'Harmattan. Marielle Rispail

1 Les textes réunis dans ce livre sont d'un apport indispensable à qui veut connaître l'histoire de la sociolinguistique. On sait combien le nom de Marcellesi est lié à sa naissance en France, par sa collaboration avec Bernard Gardin et la publication du premier ouvrage français d'initiation à ce domaine de recherche Introduction à la sociolinguistique - La linguistique sociale, en 1974. C'est aussi à Marcellesi qu'on doit une réflexion à la fois nuancée et rigoureuse sur la question des langues dites régionales, promues ainsi objets de recherche, et la fameuse notion de « polynomie ».

2 Mais comme le soulignent Thierry Bulot et Philippe Blanchet dans leur avant-propos, on peut avoir du mal à retracer ensuite le parcours et la pensée de Jean-Baptiste Marcellesi. L'auteur s'est en effet consacré à l'animation du laboratoire de Rouen et à ses activités politiques. Ses textes ont été publiés dans des revues ou des Actes de colloques, souvent épars: il était temps de les regrouper pour en souligner l'unité, l'originalité et la place qu'ils tiennent dans la sociolinguistique actuelle. Thierry Bulot et Philippe Blanchet ont donc recherché, choisi, classé, ces textes en trois parties: Epistémologie de la sociolinguistique, Langue maternelle et sociolinguistique, Polynomie et sociolinguistique du corse. Si les trois termes forment un tout, l'ensemble de l'ouvrage avance à partir d'une réflexion générale, qui définit peu à peu la place première de la sociolinguistique, au centre des Sciences du langage, et de la linguistique en particulier, vers l'étude d'un cas particulier, la langue corse et ses variations, dans le contexte particulier qu'on connaît.

3 Ces textes, même s'ils ont 20 ou 30 ans, touchent à la fois par leur justesse, leur aspect parfois visionnaire et leur modestie non dénuée d'humour. Par exemple, dans le premier, daté de 1980 et paru dans La Pensée $n^{\circ}$ 209, l'auteur tente de situer la sociolinguistique par rapport à la « linguistique formelle », et il définit ainsi son objet : 
«ce que les optimistes appelleront une discipline et les pessimistes une étiquette : la sociolinguistique » (p. 35). Dans le dernier texte sur la langue corse, publié en 1999 dans les C.I.L. de $\mathrm{L} \mathrm{n}^{\circ} 102$, l'auteur pose le problème de la reconnaissance des langues, de leurs variétés orales face à la compréhension des auditeurs et des indicateurs d'après lesquels on pourrait tracer une « géographie du corse ». Ces recherches non seulement participent à la vitalité actuelle de recherches sur les variations en langues régionales, mais aussi militent pour une "sociolinguistique pratique » qui irait à l'encontre des "pratiques normatives» souvent prônées en langue régionale, sous prétexte d'efficacité: «la sociolinguistique des langues minoritaires incite plutôt à parler comme on peut, sans attendre la norme ».

De la sociolinguistique à l'analyse de la situation corse, Jean-Baptiste Marcellesi trace un itinéraire de chercheur exemplaire et unique, à la fois soucieux de définitions claires (cf. p.152 pour le bilinguisme par exemple), de démarches méthodologiques essentielles (recenser les locuteurs, séparer les langues, cf. p. 128-129), de références communes ou de différenciations conceptuelles (hégémonie/domination par exemple, p. 166, ou langue/dialogue/minoration p.134), d'encouragements enthousiastes aux autres chercheurs (cf. p. 134 : « un domaine donc à travailler !»), de travail en équipe.

5 Au-delà des convictions défendues, se dévoile une nécessaire tolérance (p. 158), condition d'une action durable et de la non ghettoïsation d'un travail. C'est ainsi que, dans cet ouvrage, se révèlent autant l'homme que le chercheur, car la recherche est portée par des valeurs revendiquées qui lui donnent sa cohérence, quels que soient ses objets d'analyse. C'est cette "humanisation" d'une entreprise de recherche que l'entretien qui initie l'ouvrage met particulièrement en valeur. Liant recherche, histoire personnelle et politique, les paroles de Jean-Baptiste Marcellesi soulignent son implication personnelle à nourrir son travail scientifique et comment celui-ci a nourri réciproquement son engagement et sa vie.

\section{AUTEUR}

\section{MARIELLE RISPAIL}

IUfM de Nice et Université Stendhal-Grenoble 3, Lidilem 